\title{
Investigation of advanced control for unified power flow controller (UPFC) to improve the performance of power system
}

\author{
Asif Ali Lund a,*, Muhammad Usman Keerio a , Mohsin Ali Koondhar ${ }^{\text {a }}$, Muhammad Ismail Jamali a \\ Abdul Qadeer Tunio ${ }^{\text {a }}$ \\ ${ }^{a}$ Department of Electrical Engineering, Quaid-e-Awam University of Engineering, Science \& Technology \\ Nawabshah
}

*Corresponding author email: asifali14mpe02@gmail.com

\begin{abstract}
Recently, global power demand has significantly increased. As this demand does not have a proportional impact on transmission capacity and power generation. The latest methods are used to improve power system performance. The Flexible Alternating Current Transmission System (FACTS) devices are applied to improve the existing transmission network capacity. The Unified Power Flow Controller (UPFC) has been selected in this study to control power flow in transmission networks and improve the power system operation. In this paper, the Artificial Neural Network Controller (ANN) proposed to overcome the problems of the existing UPFC controller and tested using the IEEE-14 bus system with various test cases. The results showed that the proposed ANN has improved the efficiency of UPFC successfully by increasing the active power flow, reducing reactive power, and improving the voltage profile. The performance of proposed ANN-based UPFC has also been compared with Proportional Integral (PI) based UPFC and with Fuzzy Logic Controller (FLC) based UPFC shows its effectiveness. The simulation results have shown that the proposed ANNbased UPFC proved its robustness in improving all power system parameters compared to PI-based UPFC.
\end{abstract}

Keywords- Power system; Fuzzy based Unified Power Flow Controller; Artificial Neural Network-based Unified Power Flow Controller; Flexible Alternating Current Transmission

Date Received: $17-11-2020$

Date Accepted: 18-01-2021

Date Published: 08-06-2021

\section{INTRODUCTION}

$\mathrm{T}_{\mathrm{h}}$ he knowledge used in the power system utilities has improved rapidly to achieve the development in the power system operation. Utilities connected in the network can draw power from generator assets of the various parts for building the power system consistency. Such conditions could cause voltage or frequency instability and line overloading [1].

To overcome these problems new transmission lines have to be built and connected with the existing interconnected power system to raise the strength \& consistency of the power system networks [2]. But the finite energy sources, environmental restriction, and time required to build another transmission system have led the specialists to find other options to increase the capacity of power in the available transmission systems. One of these effective alternatives is FACTS devices. In the last two decades, FACTS devices have completed extreme interest as a means to enhance the performance of transmission networks [3].

Although all FACTS devices are efficient for distinct power system operations, anyway, Unified Power Flow Controller (UPFC) has gained epic popularity between them. UPFC has been recognized as a through multivariable FACTS device because it combines the objectives of various FACTS devices. UPFC can propose to assist together for regulation phase angle, voltage regulation, \& control of both powers flows individually transferred over the line [4]. FACTS stands for "Flexible Alternating Current Transmission Systems". This technology combines electronics-based controllers to mend manageability and enhances the power transfer ability of transmission networks [6]. In the behind time of the 1980s, the EPRI in the US-guided the basic research of FACTS to hold the adaptability and quality of energy frameworks by utilizing Power electronic controllers. This investigation has been given in the IEEE conference and workshops in the global meeting formulated by Electric Power Research Institute (EPRI) in Cincinnati, Ohio September in 1990 [7].

FACTS controllers can provide many significant benefits to transmission networks as follows [5].

i. FACTS controllers provide power flow control over power lines

ii. FACTS controllers raise to power transfer ability of the power transmission networks.

iii. FACTS controllers improve overall system security.

iv. FACTS controllers reduce the overload and short circuit current

v. Reduce reactive power flow, hence enabling the line to pick much active power.

vi. FACTS controllers enhance power line's stability dynamically. 
vii. FACTS controllers increment the stacking capacity of the transmission lines contrasted with their thermal abilities.

\section{A. Objectives}

- The shunt converter operates exactly as STATCOM for reactive power compensation and voltage Stabilization.
- UPFC consists of two basic switching power converter namely series and shunt converter connected to each other through a dc- link capacitor

FACTS controllers are classified based on the idea of operation or the way of connection to the transmission network. This classification is summarized in figure 1 .

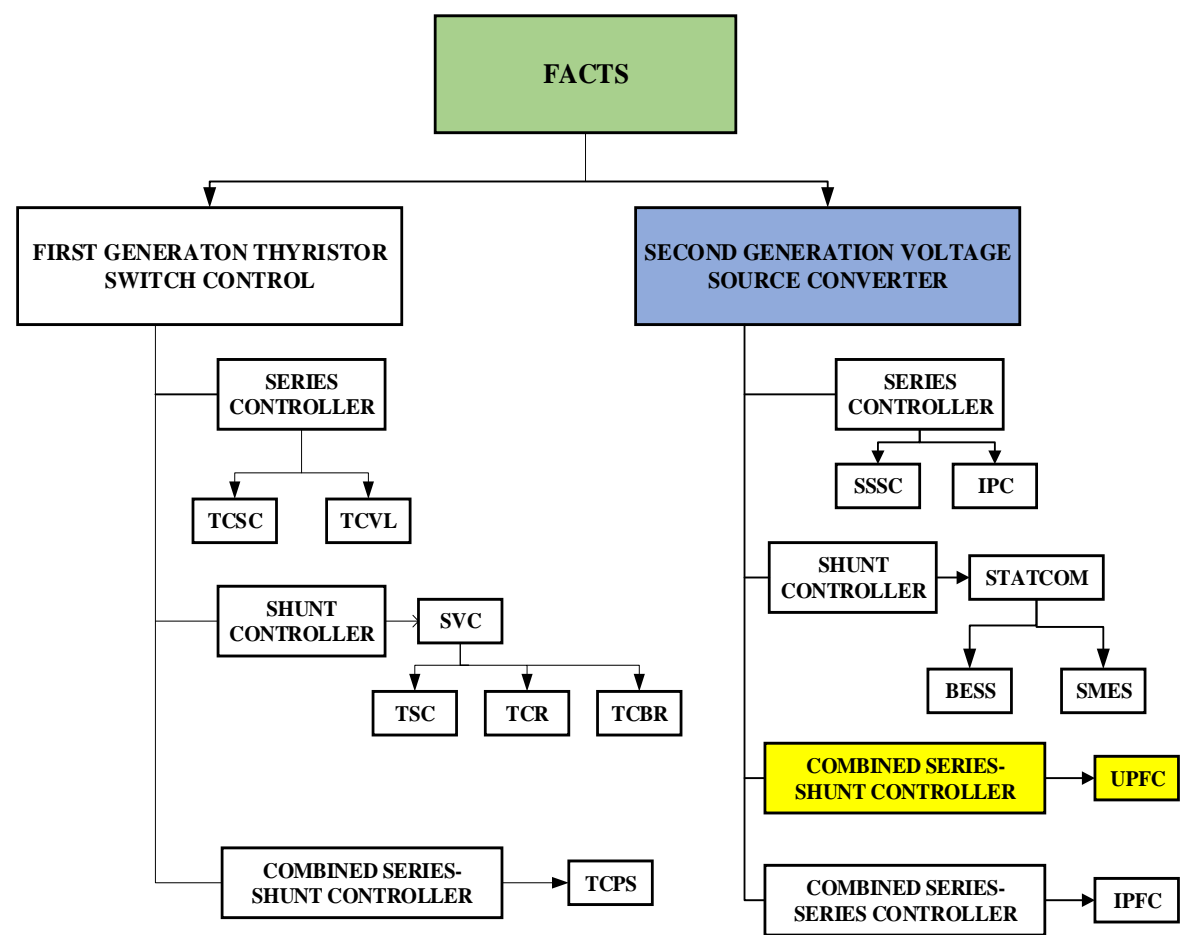

Fig. 1: FACTS devices Classification [5]

\section{B. $U P F C$}

The UPFC is a Flexible Alternating Current Transmission System (FACTS) device because it may separately control network parameters is containing the phase angle, voltage, and impedance. The UPFC consists of an SSSC, and a STATCOM linked consecutive over DC interface capacitor shown in figure 2 .

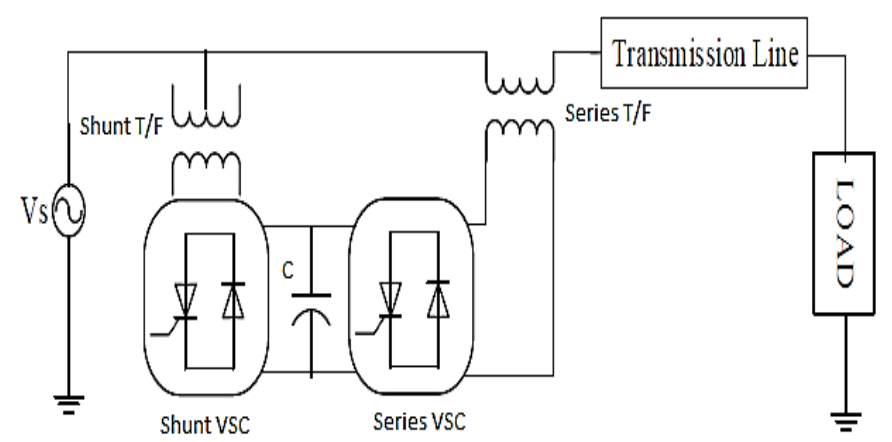

Fig. 2: Circuit diagram of UPFC [8]
The Static Synchronous Series Compensator is a voltage source controllable, and the Static Synchronous Compensator is a power source controllable [8]. The three-phase transformer connects STATCOM to the AC system network and produces real energy for SSSC consumption. The STATCOM also helps to compensate for the reactive power by assisting the transmission network. By inserting the $\mathrm{AC}$ voltage of the adjustable phase and magnitude into the power supply, the SSSC recovers voltage drops which improve reactive and active power transmission. Both converters will autonomously swap reactive power on terminals [7]. 


\section{ANN Controller-Based UPFC}

Artificial neural network controller for various control strategies for UPFC has been presented. However, all the controllers are used for damping oscillation and transient stability improvement in the power network. ANN controllerbased UPFC was reported in [15] to maintain the active power flow of the power system network. ANN controller is used to designing the internal controller of SSSC, STATCOM to improve steadiness in the power system network. In all these papers, the simulations have conducted in MATLAB software because there is no block of ANN is available in PSACAD. In [16] one neuron ANN-based UPFC is implemented to control voltage at only one bus of four bus system. Also, the accuracy of the proposed controller is low since there is only one neuron is used in the design of the ANN Controller. In [17], ANN-based UPFC is used to analyze the power flow dynamically, where $\mathrm{ANN}$ is used only for shunt controllers.

Table 1: Summary of the different UPFC controllers and their limitations

\begin{tabular}{|c|c|c|c|}
\hline Control Method & $\begin{array}{l}\text { Controlled } \\
\text { Parameters }\end{array}$ & Limitation & References \\
\hline $\begin{array}{l}\text { Phase Shifter } \\
\text { Controller-Based }\end{array}$ & $\begin{array}{l}\text { Mitigating SSR } \\
\text { caused by series }\end{array}$ & $\begin{array}{l}\text { It can't control the reactive power flow } \\
\text { through transmission lines and increases }\end{array}$ & \multirow{6}{*}{ [11-14] } \\
\hline Decoupled & $\begin{array}{ll}\text { It } & \text { can } \\
\text { control the }\end{array}$ & $\begin{array}{l}\text { It is not applicable when the } \\
\text { transmission line parameters change }\end{array}$ & \\
\hline $\begin{array}{l}\text { Cross - Coupled } \\
\text { Controller-Based } \\
\text { UPFC }\end{array}$ & $\begin{array}{l}\text { Voltage Regulation } \\
\text { Reactive, and active } \\
\text { power flow control. }\end{array}$ & $\begin{array}{l}\text { It has a limitation in regulating the } \\
\text { DC link capacitor voltage since its } \\
\text { design does not study the operation of } \\
\text { dynamics of the DC capacitor. }\end{array}$ & \\
\hline $\begin{array}{l}\text { Coordination } \\
\text { Control Based } \\
\text { UPFC }\end{array}$ & $\begin{array}{l}\text { Control of active } \\
\text { and reactive power } \\
\text { flow }\end{array}$ & $\begin{array}{l}\text { The complexity of the control system } \\
\text { has increased. Furthermore, the use of PI } \\
\text { controller results in low superiority of }\end{array}$ & \\
\hline $\begin{array}{l}\text { Nonlinear Control } \\
\text { of UPFC }\end{array}$ & $\begin{array}{l}\text { Improve the power } \\
\text { flow control and } \\
\text { damping of power }\end{array}$ & $\begin{array}{l}\text { The nonlinear controller is implemented } \\
\text { based on nonlinear differentials } \\
\text { equations and the solutions of these }\end{array}$ & \\
\hline \begin{tabular}{|l|} 
Artificial \\
Intelligent \\
Controller of \\
UPFC \\
Fuzzy Logic \\
Controller Based \\
UPFC \\
\end{tabular} & $\begin{array}{l}\text { Damp oscillation } \\
\text { and improv } \\
\text { ransient stability } \\
\text { Voltage stability, } \\
\text { damp oscillations, } \\
\text { active and reactive } \\
\text { power flow in } \\
\text { power system }\end{array}$ & $\begin{array}{l}\text { To produce the training patterns of the } \\
\text { controller for huge network is very } \\
\text { complicated } \\
\text { So far, FLC- based UPFC has been } \\
\text { applied only for steady state analysis } \\
\text { and it doesn't apply for dynamic power } \\
\text { flow control }\end{array}$ & \\
\hline
\end{tabular}

\section{METHODOLOGY}

This research includes modeling of UPFC in PSCAD/EMTDC software. Also, modeling of series and shunt controllers of UPFC are discussed. The control strategies for both converters of P I-b a s ed UPFC controller are implemented. Also, the FLC-based UPFC development will be addressed with PSCAD/EMTDC tools. Finally, both FLC and PI controllers are provided with the UPFC shunt and series control constraints for the IEEE-14 bus network.

\section{A. Developed Model of UPFC in PSCAD}

The steady-state models of UPFC have been implemented in the previous literature. However, the steady-state model may be used only for the planning \& designing of the system. Therefore, the transient model of UPFC has proposed to investigate the power network by real time analysis. In this study, UPFC will develop to improve power flow and power system stability in the transmission network. A UPFC model in PSCAD has been developed. On both ends of the transmission line, two generators are installed. Transformers of series \& shunt are used to connect UPFC to the power system. It consists of two VSCs attached via a DC link condenser. The VSC shunt STATCOM is where the SSSC is the VSC series. A three-stage six-pulse operated bridge is designed for each converter. Switching devices can be made with anti-parallel diodes with IGBTs for both converters. 


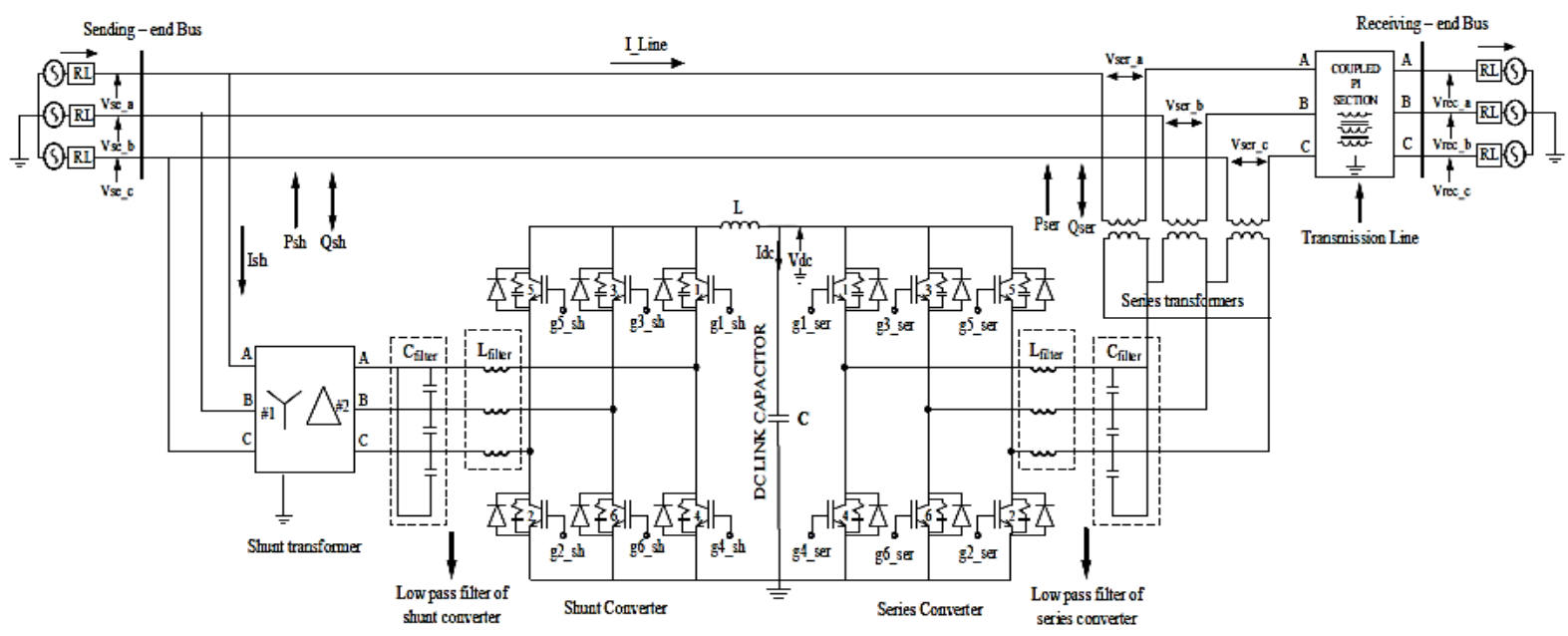

Fig. 3: Model of UPFC Developed in PSCAD/EMTDC Software

A. Steps of methodology

- To design an IEEE-14 bus system in combination with PSCAD software version 4.5.1.

- To incorporate the PI, fuzzy, and ANN based UPFC to investigate their performance.

\section{B. UPFC Modes of Operation}

UPFC shunt and series converters have different modes of operation depending on the reference signals. The reference signals could be a current reference or voltage reference. Figure 4 illustrates the mode of operation for both converters of UPFC based on current and voltage references.

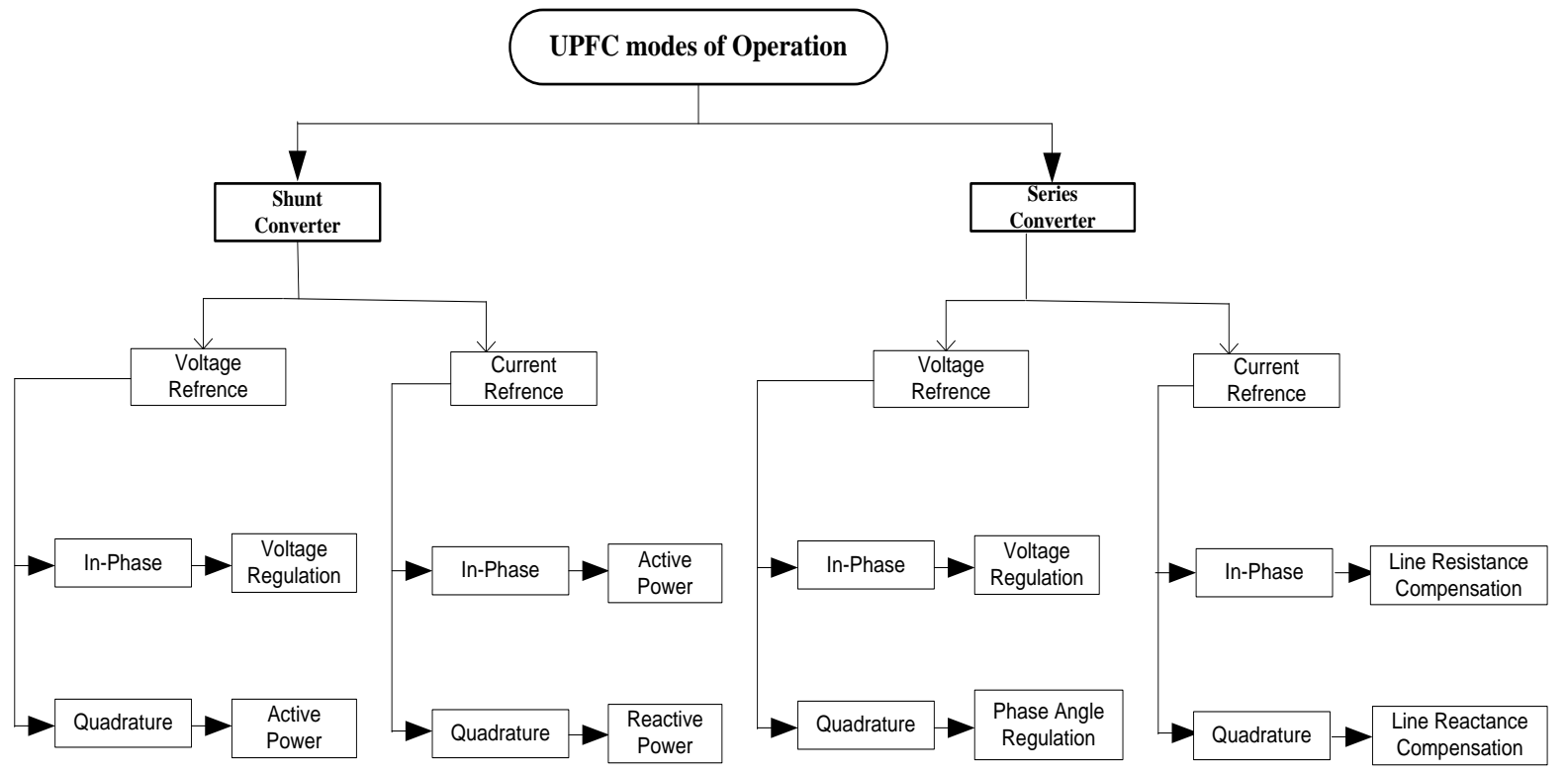

Fig. 4: Modes of Operation for shunt and series Converters of UPFC [10]

\section{TEST SYSTEM MODELING}

IEEE-14 test systems are used which in turn presents the effectiveness of the proposed ANN-based UPFC. PSCAD software is used to simulate for purpose of explaining the performance of ANN over the improvement of UPFC in the transmission network. 


\section{a. IEEE-14 Bus System}

Bus 2 and 1 Out of 14 buses is test device generator buses and buses $3,6,8$ are linked to a synchronous condenser to provide reactive power support to the network. The remaining 11 are load buses. The per-unit values of the alternator and Transmission line are $138 \mathrm{kV}$ and 100 MVA. The Voltage failure Point Indicators and Line Stability Factor, stability index is applied to determine an optimal UPFC region within the
IEEE-14 bus network. If at least one transmission network has an increasing value of LQP or VCP indices, adding a certain sum of all active and reactive loads on all buses. The line indices raised one that is considered to be an unstable line and the UPFC placement location. The same method has been applied for the IEEE-14 bus network, and the index value for lines 9-14 reaches 1 . Therefore in the IEEE-14 bus system line, 9-14 is the optimum position of the planned UPFC. Figure 5 presented the IEEE-14 bus system and the UPFC location.

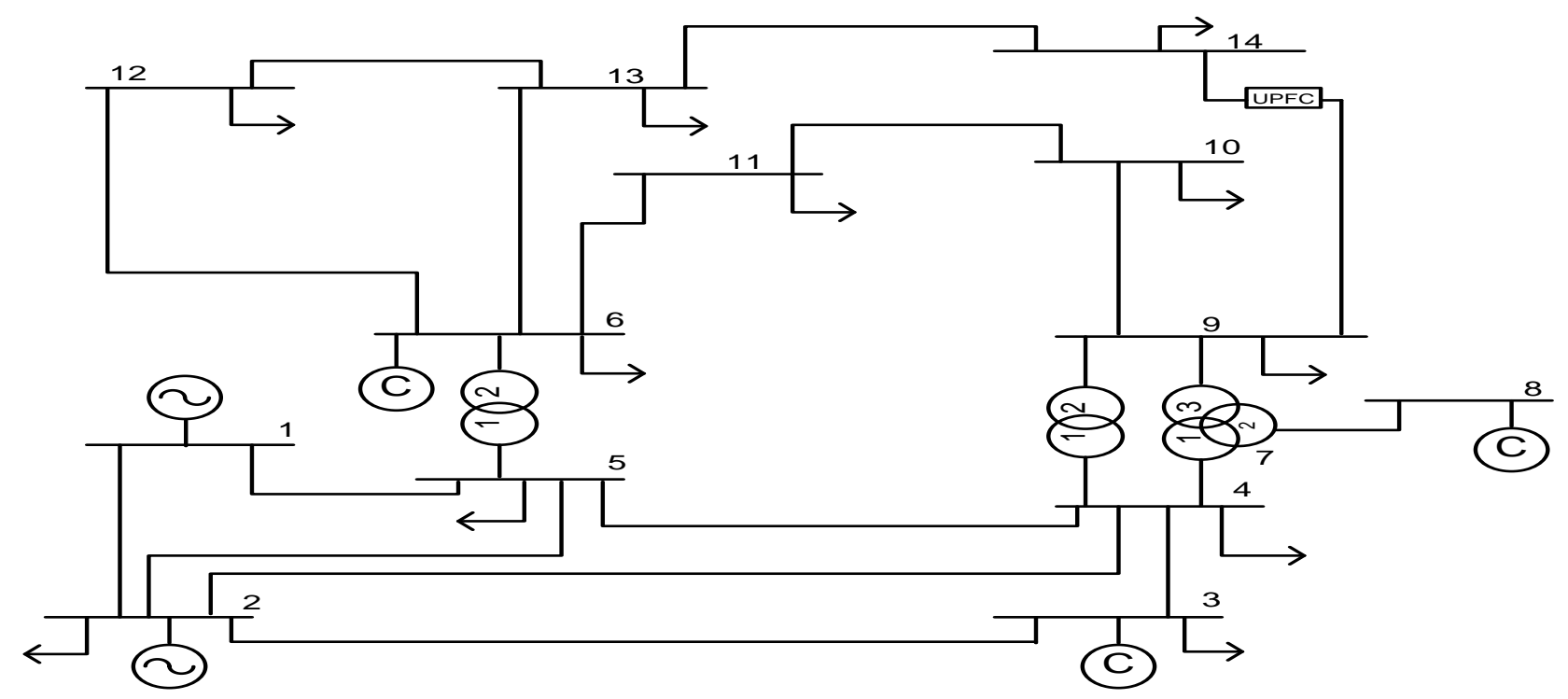

Fig. 5: IEEE-14 Bus System [9]

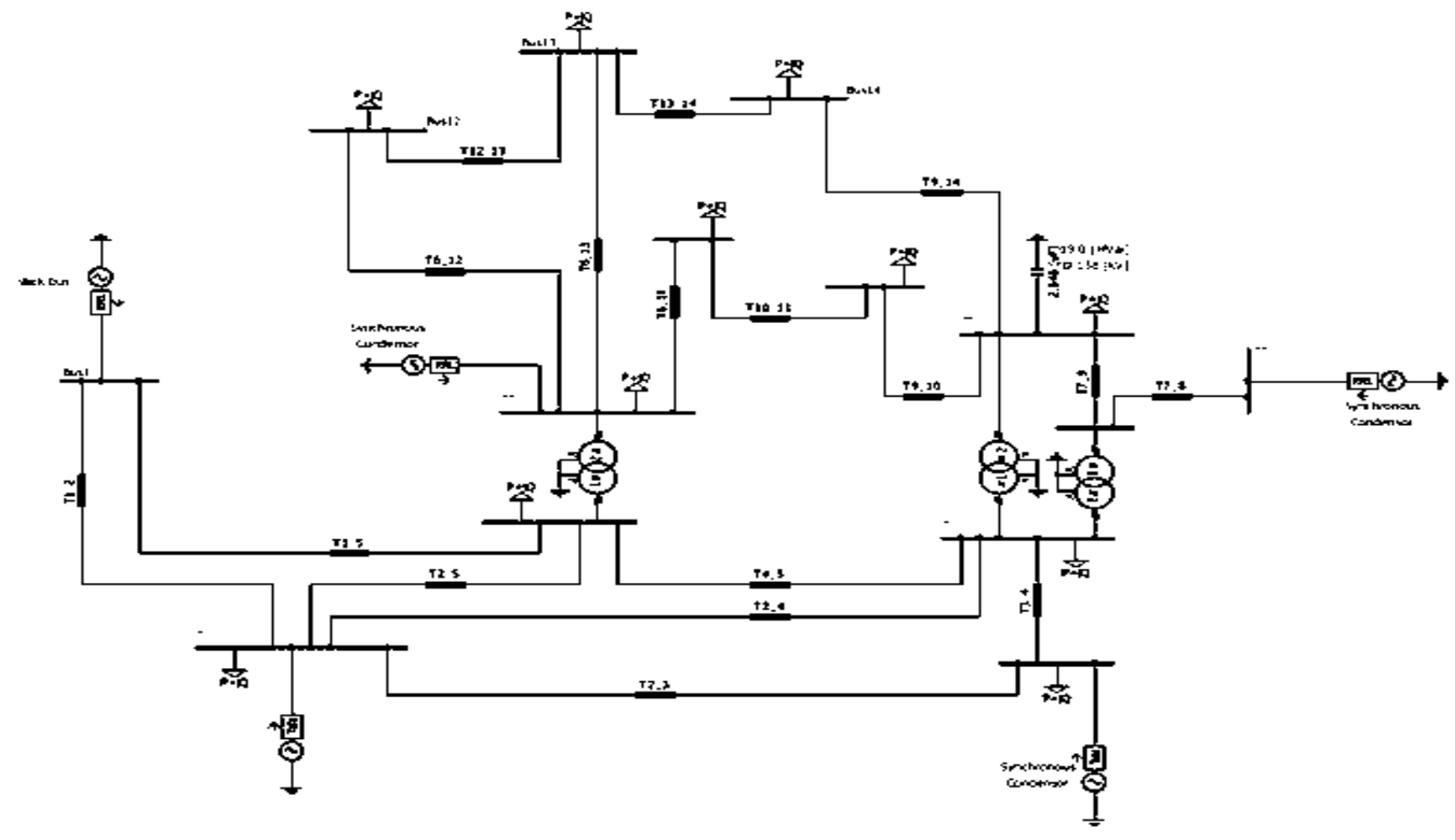

Fig. 6: IEEE-14 Bus System Model in PSCAD/EMTDC [9] 


\section{RESULTS AND DISCUSSION}

In this research modeling and validation of the proposed ANNbased UPFC using the IEEE-14 bus test system. PSCAD/MATLAB software is used to design a model of the test system. The simulation results of the test system with proposed ANN_UPFC, FLC_UPFC, and PI_UPFC for all power network boundaries are also presented. In the last, their comparison of performance between ANN_UPFC and FLC_UPFC will be discussed.

\section{A. SIMULATION RESULTS OF IEEE-14 BUS SYSTEMS}

The IEEE- 14 bus system is Simulink except UPFC to find the base per unit necessary for modeling of proposed UPFC controller. The values of the power system like active power, reactive power flow, and bus voltage, obtained by comparing the values of power systems before and after implementation will evaluate the efficacy of the UPFC. The simulation results are divided into two parts:

A) Performance analysis for proposed ANN-based UPFC connected at buses 9-14.

B) Performance of proposed ANN-based UPFC for power loss reduction and voltage profile improvements.

Conventional PI and FLC-based UPFC is also compared with ANN _UPFC controllers

\section{B. CONTROL OF ACTIVE POWER AT SENDING BUS}

Figure 7 illustrates the response of suggested ANN UPFC; FLC based UPFC and with PI UPFC at bus number 9 i-e sending bus.

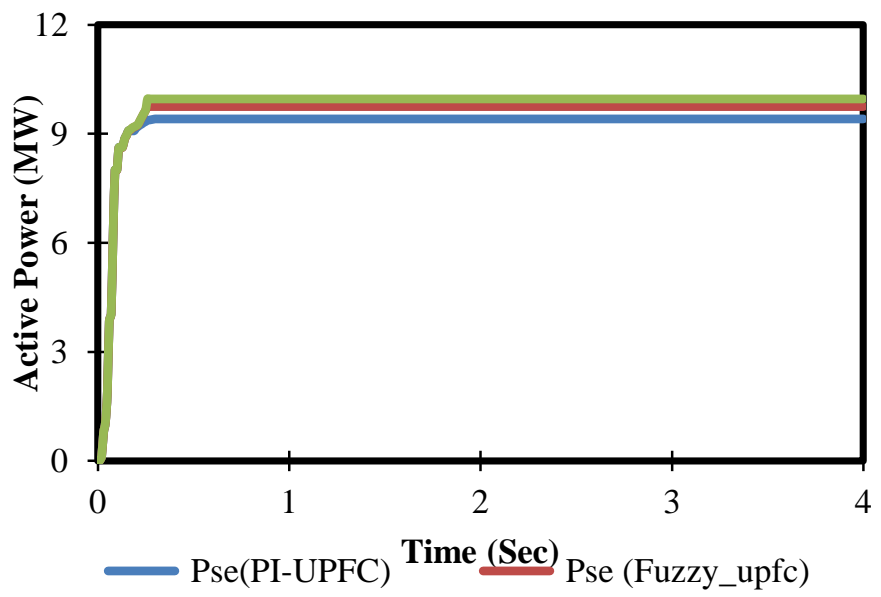

Fig. 7: Active Power Flow at Sending Bus

Figure 7 shows that the measured active power flow via sending bus with PI_UPFC, FLC_UPFC, and ANN_UPFC is $9.4081 \mathrm{MW}$ (Mega Watt), 9.7554MW, and $9.9548 \mathrm{MW}$ respectively. Thus, ANN_UPFC has enhanced the active power flow compared to FLC_UPFC. Thus, the above results show that ANN_UPFC is more effective than FLC_UPFC for active power control at sending buses.

\section{Control of Reactive Power at Sending Bus}

Figure 8 show the results of suggested ANN UPFC, fuzzy UPFC and with PI UPFC at bus number 9 i-e sending bus.

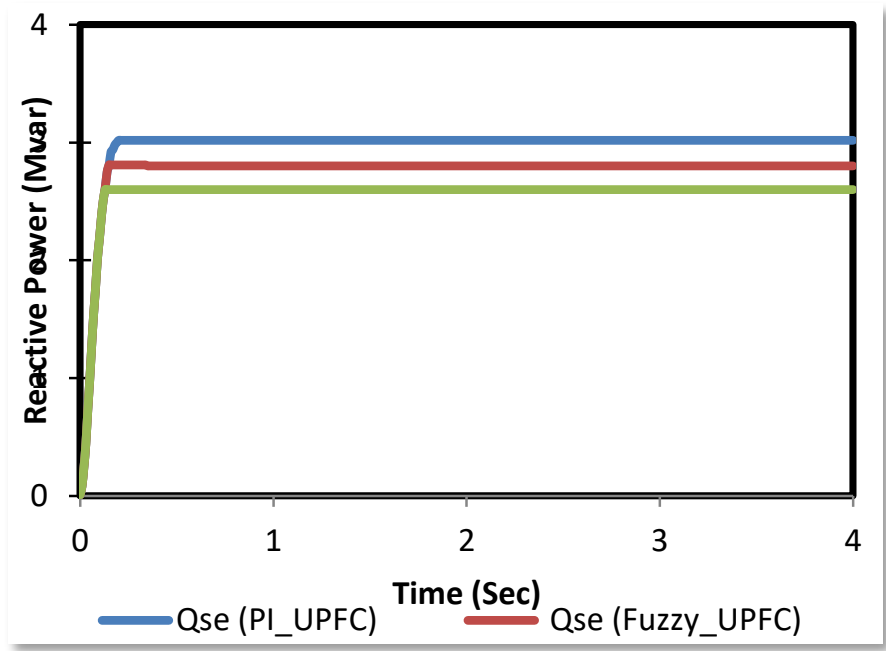

Fig. 8: Reactive Power Flow at Sending Bus

Figure 8 shows that measured reactive power flow via sending bus with PI_UPFC, FLC_UPFC, and ANN_UPFC is 3.026646 MVar, 2.8004Mvar, and 2.5104 Mvar respectively. Thus, the proposed ANN_UPFC has significantly decreased the reactive power compared to FLC_UPFC. Thus, in terms of reactive power control at Sending Bus, the ANN-based UPFC is superior to the FLC based UPFC.

\section{Voltage Profile Improvement at Sending Bus}

Figure 9 (a) shows the response of PI UPFC, Fuzzy UPFC and with ANN UPFC at bus number $9 \mathrm{i}$-e sending bus, whereas Figure 9 (b) shows the magnified view of the voltages of all controllers.

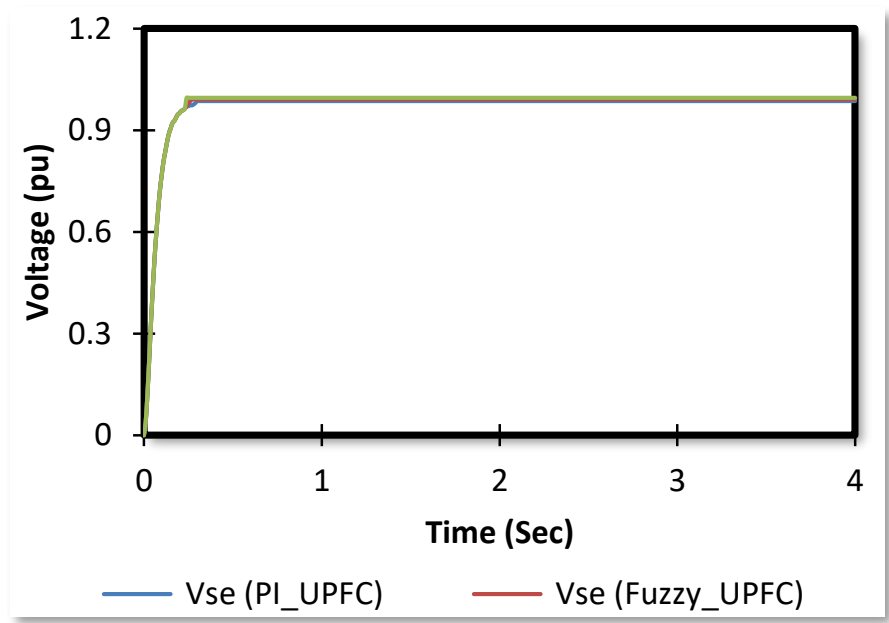

Fig. 9 (a) Voltage at Sending Bus 


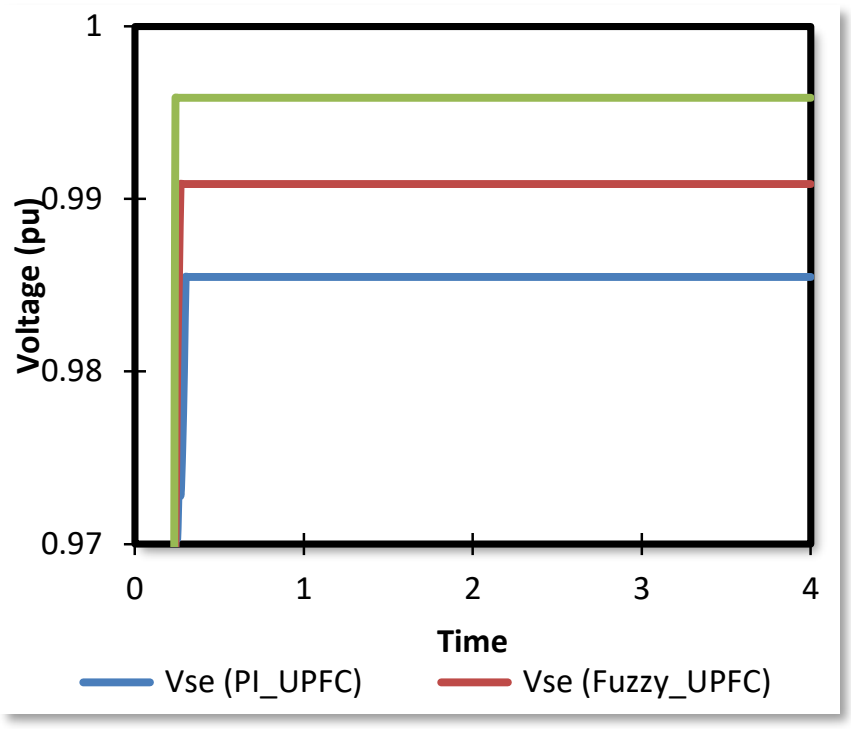

Fig. 9 (b) Zoomed Voltage at Sending Bus

Figure 9 (b) can be clearly understood that measured voltage at sending bus with PI, FLC, and ANN-based UPFC is $0.9821 \mathrm{pu}, 0.9854 \mathrm{pu}$, and $0.9908 \mathrm{pu}$ respectively. Thus the voltage profile of ANN_UPFC is significantly higher as compared to FLC_UPFC.

\section{E. CONTROL OF ACTIVE POWER AT RECEIVING BUS}

Figure 10 shows that the response suggested with FLC_UPFC, PI_UPFC and ANN_UPFC at bus number 14 i-e receiving bus. Figure 10 shows that measured active power flow through the receiving bus with PI_UPFC, FLC_UPFC, and ANN_UPFC is 9.3254 MW, 9.8028MW, and $9.9048 \mathrm{MW}$ respectively. ANN_UPFC has enhanced active power compared to FLC_UPFC. The proposed ANN-based UPFC, therefore, has better performance in comparison of active power control in receiving bus than the FLC based UPFC.

\section{F. Control of Reactive Power at Receiving Bus}

Figure 11 shows the results with PI_UPFC, FLC_UPFC and proposed ANN_UPFC at bus number 14 i-e receiving bus. Figure 11 shows that reactive power flow measured by the receiving bus is 3.1058 MVar, 2.9081 MVar, and 2.6032 MVar respectively; using PI-based UPFC, FLC-based UPFC, and ANN-based UPFC. It is therefore obvious that ANN-based UPFC has significantly declined the reactive power equating to

\section{G. Voltage Profile Improvement at Receiving Bus.}

Figure 12 (a) shows the response of PI_UPFC, fuzzy_UPFC, and with ANN_UPFC installation at bus number 14 i-e receiving bus, whereas figure 12 (b) shows the magnified view of the voltages of all controllers.
FLC based UPFC. The reactive power control at receiving bus ANN_UPFC is superior to FLC_UPFC.

Fig. 10: Active Power at Receiving Bus
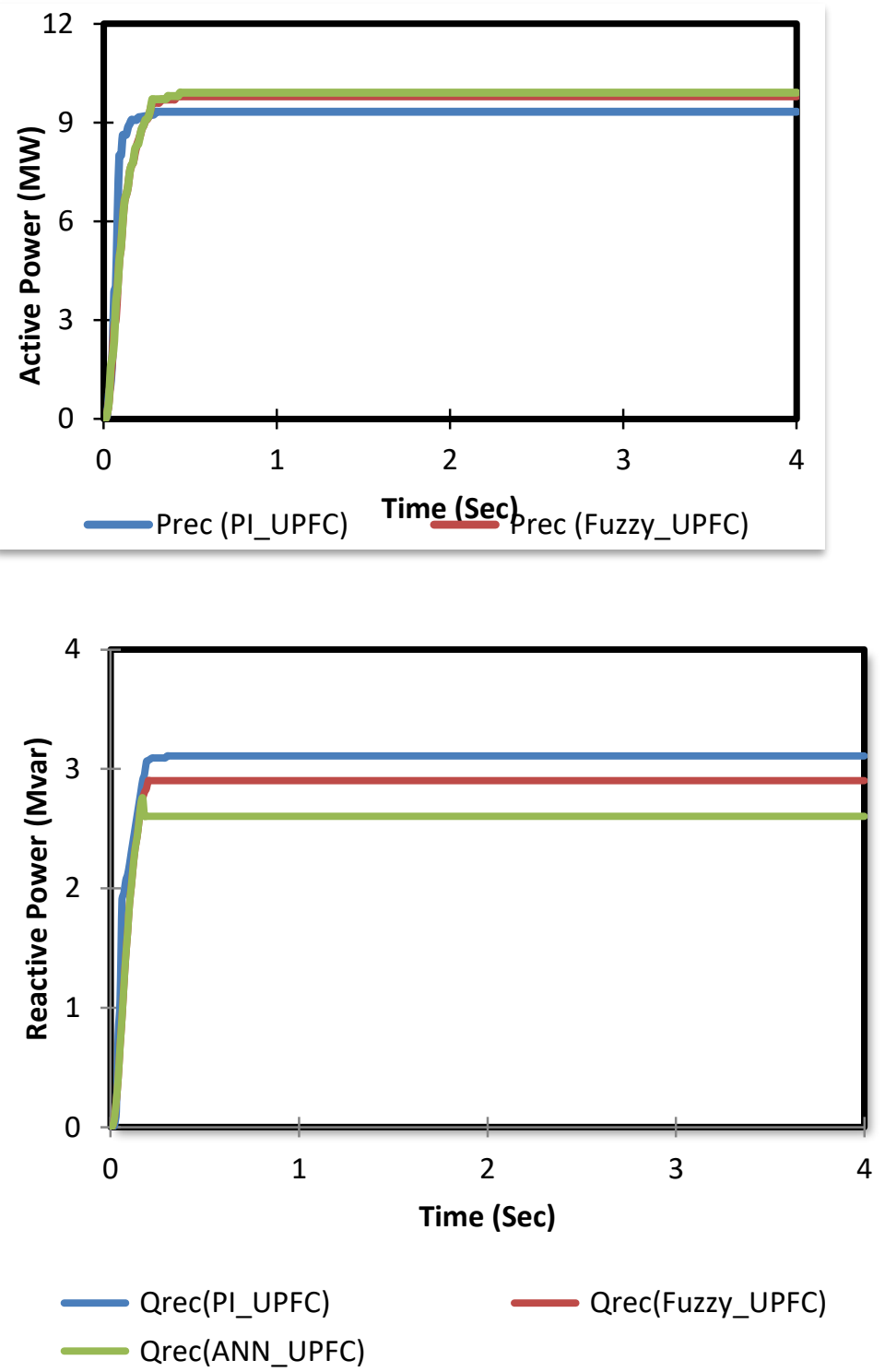

Fig. 11: Reactive Power at Receiving Bus 


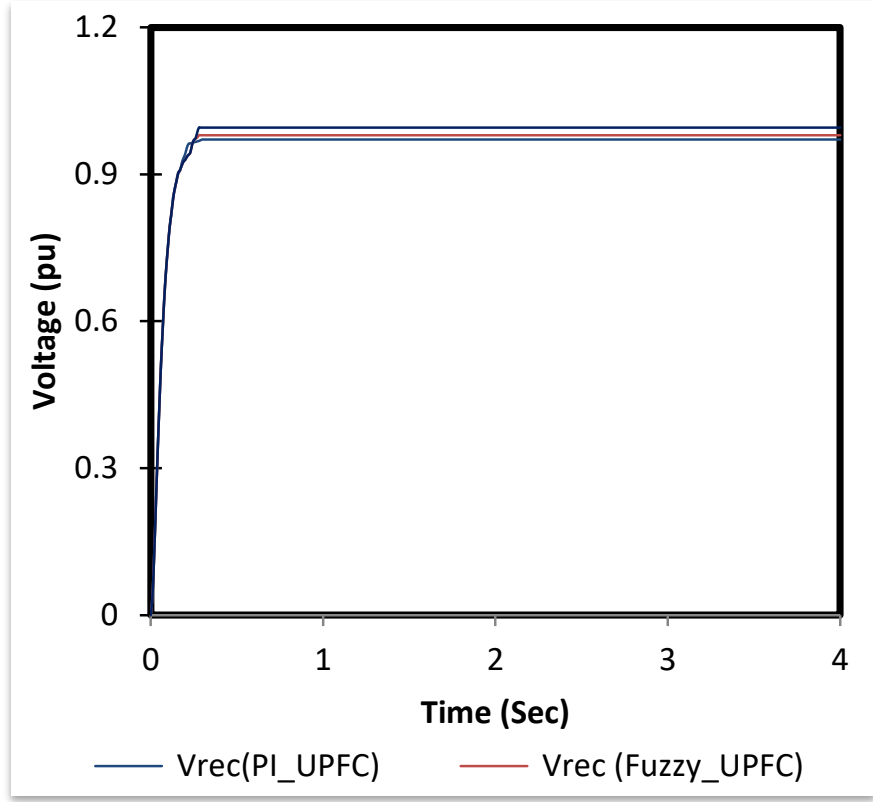

Fig. 12 (a) Voltage at Receiving Bus

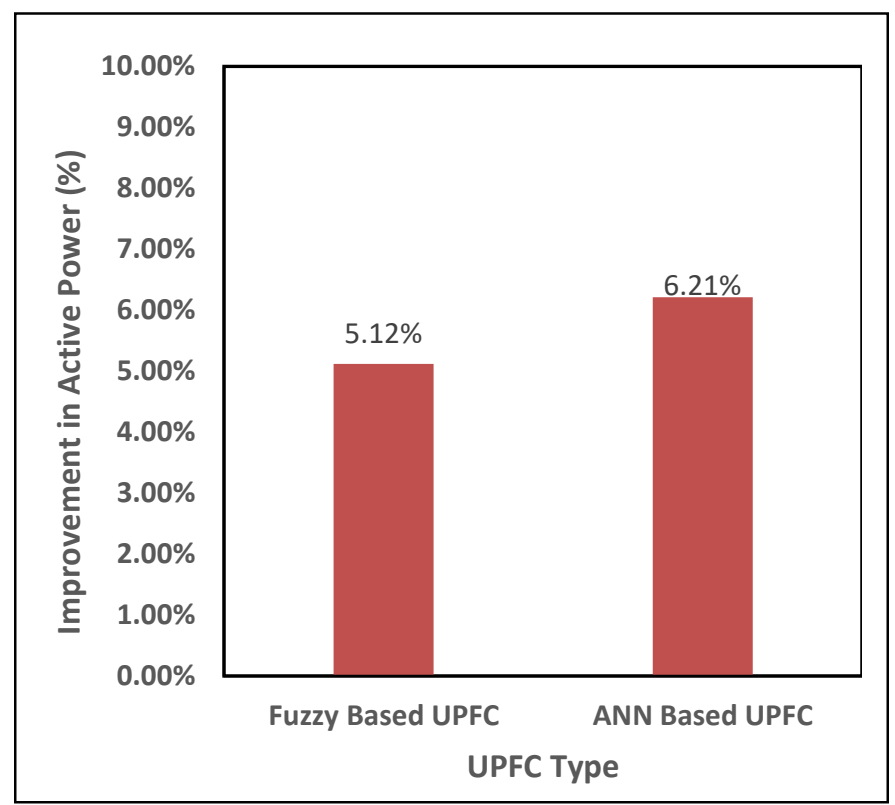

Fig. 13: Percentage- wise improvements in Active Power by UPFC Controllers

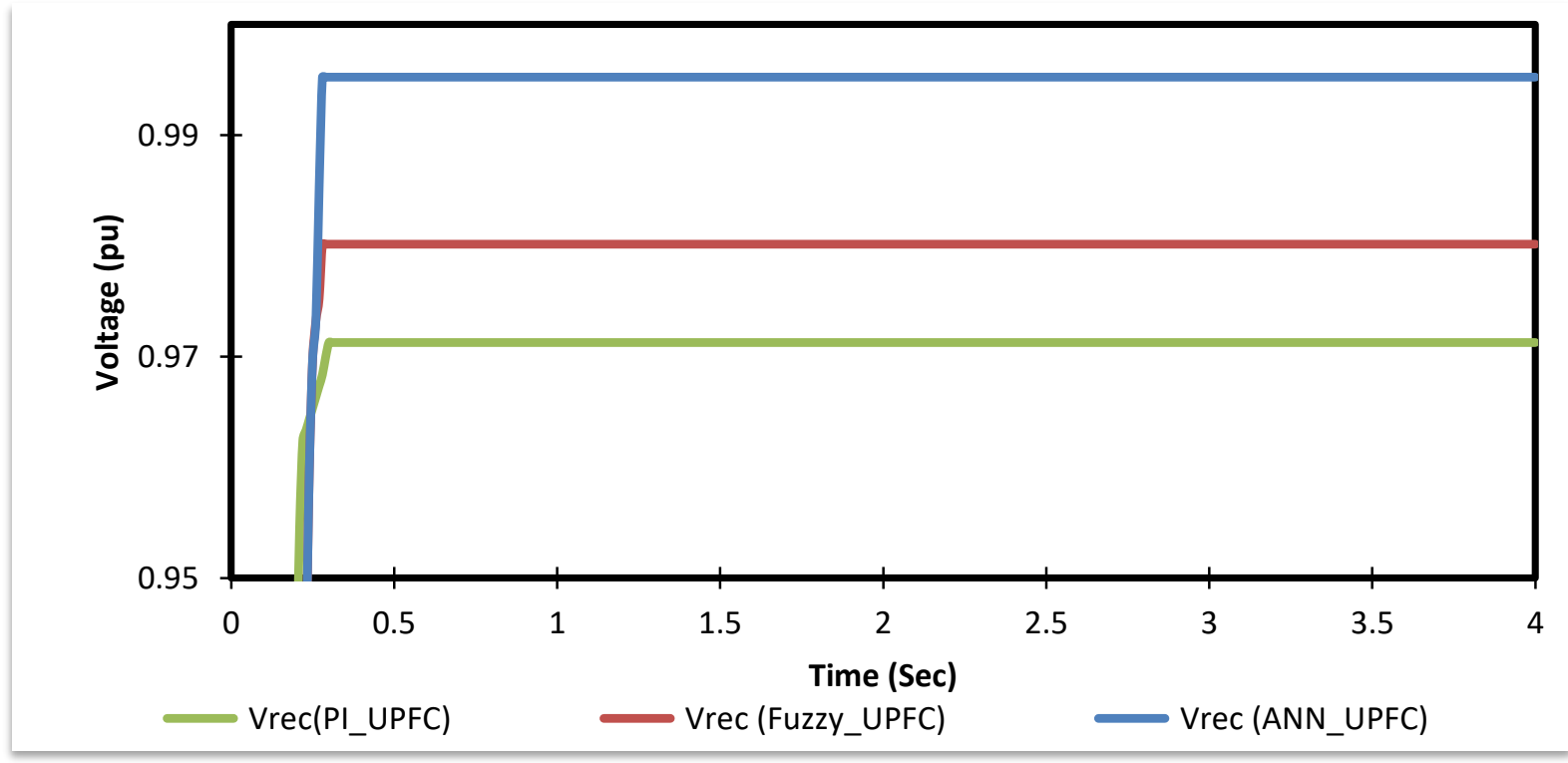

Fig. 12 (b) Voltage at Receiving Bus

It has been observed from Figure 12 (b) that the measured voltage at receiving bus with PI_UPFC, with FLC_UPFC and ANN_UPFC, is $0.9636 \mathrm{pu}, 0.9712 \mathrm{pu}$, and $0.9801 \mathrm{pu}$ respectively. Thus, ANN-based UPFC has a marginally superior voltage profile related to FLC-based UPFC.

To evaluate their performance, PI_UPFC, FLC_UPFC and ANN_UPFC have investigated the response from a number of power grid factors, including Active, Reactive, and Voltage for the IEEE-14 bus network. Figure 13 shows percentage-wise improvement in active power by FLC based UPFC and ANNbased UPFC controller while figure 14 illustrates the percentage-wise decrement in reactive power by FLC \& ANNbased UPFC controller.
It is illustrated in figure 13 with respect to percentage enhancement in active power by FLC controller-based UPFC is by $5.12 \%$ while using ANN-based UPFC; it has been enhanced to $6.21 \%$ at the reaching end bus of the network. As it is clear from figure 14 shows that reactive power decreased by FLC UPFC is $6.36 \%$ while planned ANN-based UPFC has decreased reactive power by $16.18 \%$. The voltage at the getting bus has also been developed by both controllers. Moreover, the same effect may be analyzed on sending buses i.e. Bus 9 with enhancement in active power flow, this causes a reduction in reactive power and improvement in voltage profile of all buses. 


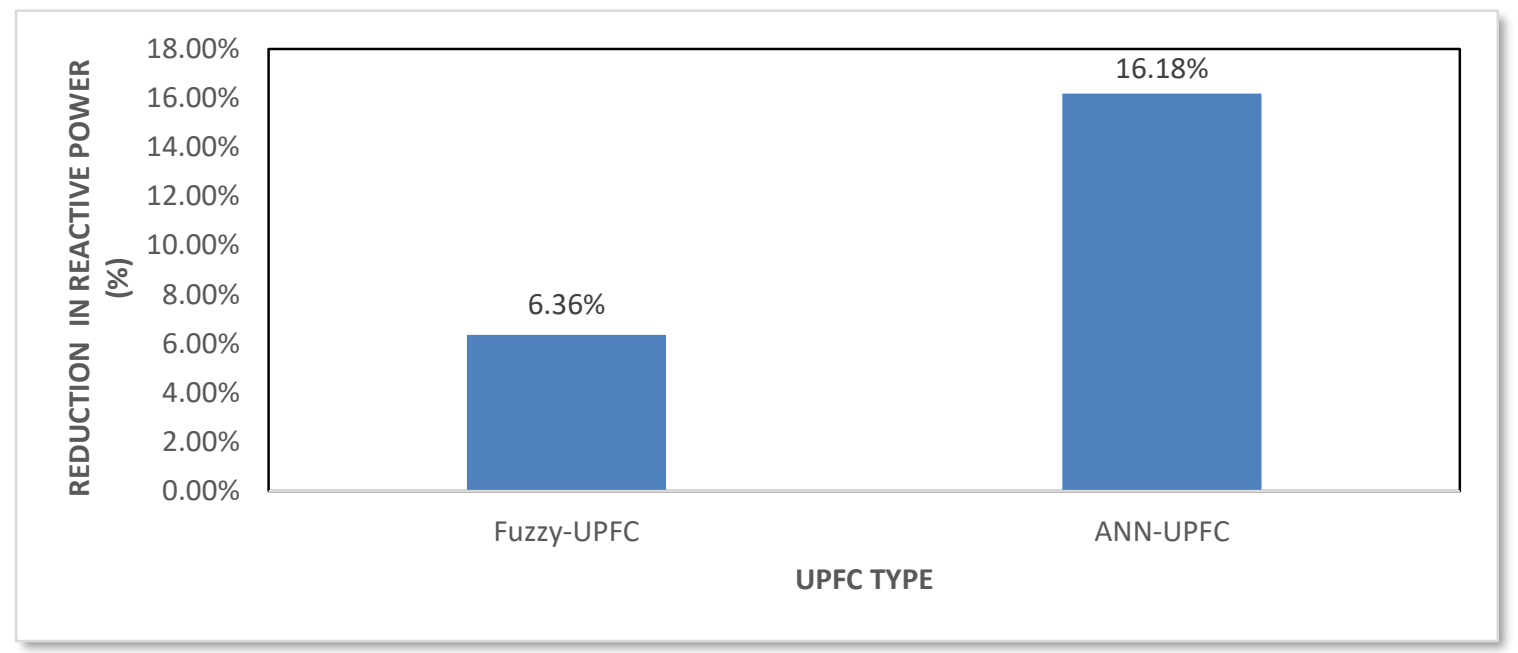

Fig. 14: UPFC based controller to reduce Reactive Power in Percentage

\section{CONCLUSION}

In literature, the steady-state model of UPFC to control the power flow in transmission lines has been proposed. However, the steady-state model is effective only for the Planning and designing of a network. The ANN-based UPFC series \& shunt controllers have made as off gird in PSCAD/MATLAB software. IEEE-14 bus has been selected to authenticate the presentation of the proposed ANN-based UPFC. Furthermore, it has achieved higher active power flow, enhanced sending, and receiving end voltages compared to fuzzy-based UPFC. The simulation results show that in the IEEE-14 bus system ANN-based UPFC has enhanced active power flow up to $6.2130 \%$ as compared to the FLC controller is $5.11 \%$.

Furthermore, it has proved that reactive power will face a reduction of $16.18 \%$ with ANN-based UPFC as compared to FLC based UPFC is $6.336 \%$.

\section{REFERENCES}

[1] A. A. Suhail, K. Jagdesh, A. A. Chandio, "Application of Fuzzy Logic Control for Performance Analysis of Transmission System Using Unified Power Flow Controller", QUEST Research Journal, vol. 16, p. 9, 1016, 2018.

[2] D. K. Raju, B. S Umre, J. S. Anjali, and B. C. Babu, "Mitigation of Subsynchronous Resonance with Fractional-order PI based UPFC controller," Mechanical Systems and Signal Processing, vol. .85,pp. 698-715, 2017.

[3] S. Ahmad, F. M. Albatsh, S. Mekhilef, and H. Mokhlis, "An approach to improve active power flow capability by using dynamic unified power flow controller," in 2014 IEEE Innovative Smart Grid Technologies - Asia (ISGT ASIA), pp. 249-254, 2014.

[4] E. Gholipour, and S. Saadate, "Improving of transient stability of power systems using UPFC," IEEE Transactions on Power Delivery, V.20 No.2, pp. 16771682, 2005.
[5] L. Gyugyi, "Unified power-flow control concept for flexible AC transmission systems," IEE Proceedings C Generation, Transmission and Distribution, vol. 139, no.4, pp. 323-331, 1992.

[6] J. Paserba, "Recent Power Electronics/FACTS Installations to Improve Power System Dynamic Performance," in 2007 IEEE Power Engineering Society General Meeting, pp. 1-4, 2007.

[7] S. Kannan, S. Jayaram, and M. M. A. Salama, "Real and reactive power coordination for a unified power flow controller," IEEE Transactions on Power Systems, vol. 19, no.3, pp. 1454-1461, 2004.

[8] A. J. F. Keri, A. S. Mehraban, X. Lombard, A. Eiriachy, and A. A. Edris, "Unified power flow controller (UPFC): modeling and analysis," IEEE Transactions on Power Delivery, vol. 14, no.2, pp. 648-654, 1999.

[9] M. Cupelli, C. D. Cardet, and A. Monti, "Voltage stability indices comparison on the IEEE-39 bus system using RTDS," in 2012 IEEE International Conference on Power System Technology (POWERCON), pp. 1-6, 2012.

[10] S. Chansareewittaya. and P. Jirapong, "Power transfer capability enhancement with optimal maximum number of facts controllers using evolutionary programming," in IECON 2011 - 37th Annual Conference of the IEEE Industrial Electronics Society, pp. 4733-4738, 2011.

[11] Chansareewittaya S. and Jirapong P., (2011) "Power transfer capability enhancement with optimal maximum number of facts controllers using evolutionary programming," in IECON 2011 - 37th Annual Conference of the IEEE Industrial Electronics Society, pp. 4733-4738.

[12] Gitizadeh M. and Kalantar M.,(2009), "A novel approach for optimum allocation of FACTS devices 
using multi-objective function," Energy Conversion and Management, V.50 No.3, pp. 682-690.

[13] Elgamal M. E., Lotfy A., and Ali G. E. M.,(2012), "Voltage profile enhancement by fuzzy controlled MLI UPFC," International Journal of Electrical Power \& Energy Systems, V.34 No.1, pp. 10-18.

[14] Zhengyu H., Yinxin N., Shen C. M., Wu F. F., Shousun C., and Baolin Z.,(2000), "Application of unified power flow controller in interconnected power systems-modeling, interface, control strategy, and case study," IEEE Transactions on Power Systems, V.15 No.2, pp. 817-824.

[15] Guo J., Crow M. L., and Sarangapani J, (2009), "An Improved UPFC Control for Oscillation Damping," IEEE Transactions on Power Systems, V.24 No.1, pp. 288-296.

[16] Ajami A., Shotorbani A. M., and Aagababa M. P, (2012), "Application of the direct Lyapunov method for robust finite-time power flow control with a unified power flow controller," IET Generation, Transmission \& Distribution, V.6 No.9, pp. 822-830.

[17] Saribulut L., M T., x0Fc, and may, (2008) "Simulation Study of Fuzzy Based Unified Power Flow Controller on Power Flow Controlling," in Power Electronics and Intelligent Transportation System, 2008. PEITS '08. Workshop on, pp. 411-415.

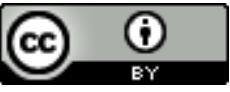

Journal of Applied and Emerging Sciences by BUITEMS is licensed under a Creative Commons Attribution 4.0 International License. 